\title{
A drinkable foreign body: acrylated resin
}

A 65-year-old schizophrenic patient had ongoing epigastric pain. Gastroscopy revealed a large foreign body ( $\bullet$ Fig. 1). Endoscopic fragmentation and retrieval were impossible ( Fig.2). The patient denied having ingested the object, which, considering its size, was plausible.

The foreign body was not dissolvable, causing symptoms and a risk of intestinal obstruction or perforation. Surgical removal was necessary ( Video 1 ). A laparoscopic gastrotomy of the anterior gastric wall to harvest the object ( $\bullet$ Fig.3) was followed by removal through a lengthened trocar incision in a retrieval bag. The gastrotomy was sutured laparoscopically. Postoperative recovery was uneventful. Physicochemical analysis of the object revealed it to be acrylated resin. The patient then admitted to "accidentally" having drunk clear paint. The chemicals contained in the paint hardened in the stomach forming a solid foreign body ( Fig.4). Intraintestinal formation of a large object is best known in form of a bezoar made up of many small foreign bodies, like in "Rapunzel syndrome", when the object is made up of the patient's own hair [1], although bezoars also occur with other material [2].

The psychiatric disorder in our patient suggested intentional ingestion of the liquid. Concealment of the facts by patients is common with deliberate foreign body ingestion [3]. Ingestion of foreign material in adults is usually intentional [3], sometimes suicidal. Paint has been used successfully to commit suicide [4].

Clinical management of ingested foreign bodies is well described [5]. Many objects pass naturally, but the rate of surgical intervention reaches 16\% [5]. Endoscopy should not delay surgical consultation.

Unusual in this case is that a liquid, in the stomach, becomes a solid object which could not have been swallowed as such. A laparoscopic approach can be a safe and efficient way to minimize trauma and minimize recovery time for the removal of such a large intestinal foreign body.

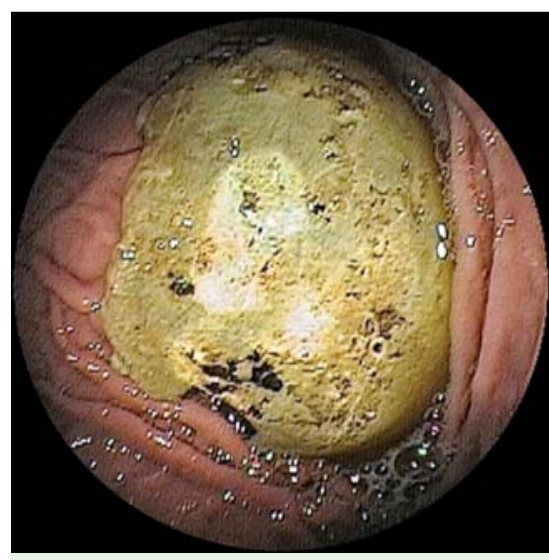

Fig. 1 Endoscopic view of a solid foreign body measuring $6 \times 8 \times 4 \mathrm{~cm}$ in the stomach.

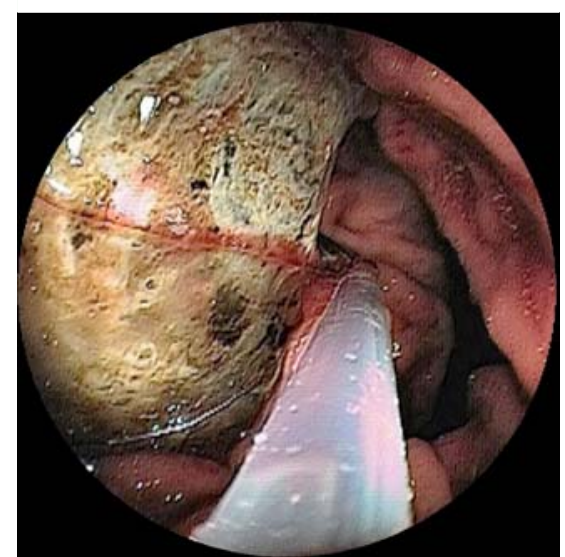

Fig.2 It was possible to place a snare around the object, but endoscopic retrieval was impossible due to its size.

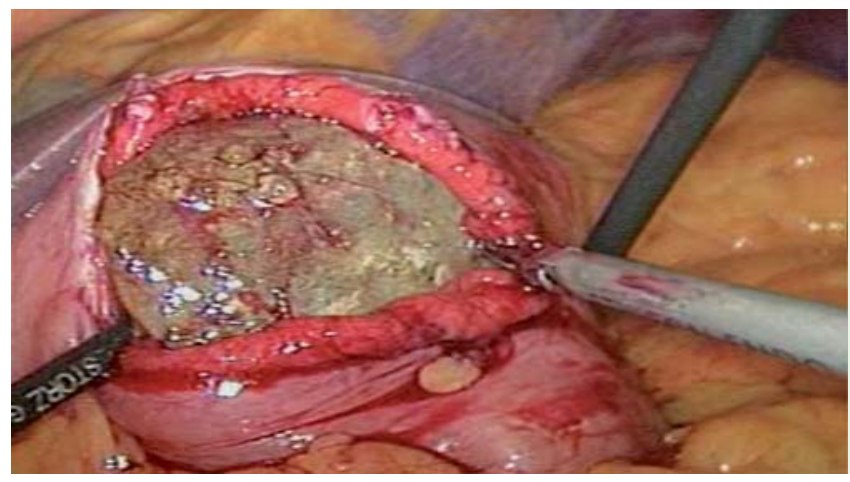

Fig.3 Intraoperative view showing the laparoscopic extrication of the foreign body after gastrotomy.

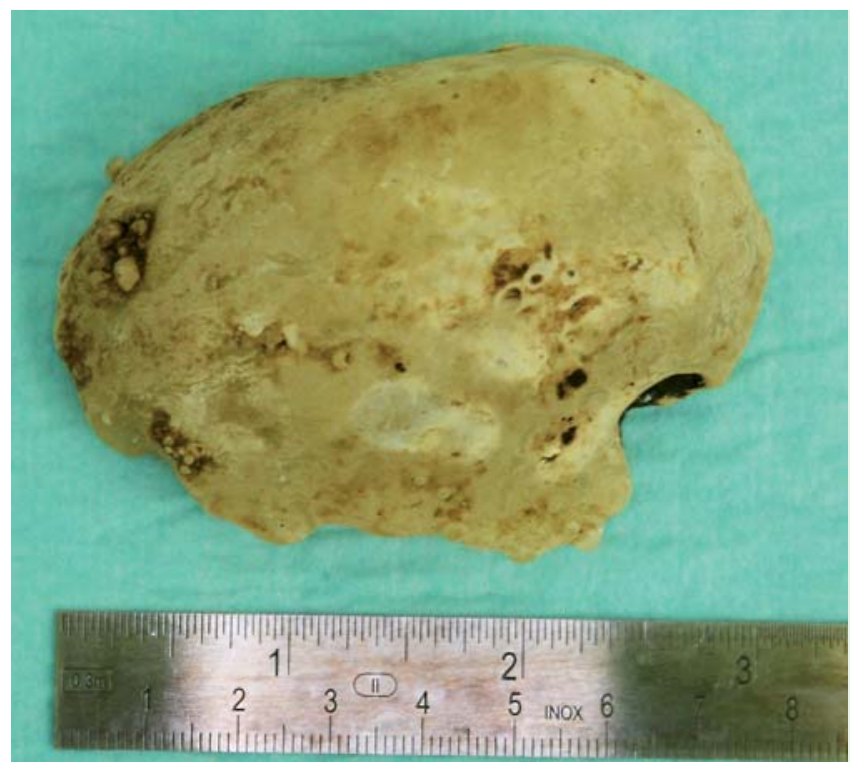

Fig. 4 View of the extricated foreign body. Physicochemical analysis revealed the foreign body to consist of acrylated resin that hardened in the stomach after the patient had, accidentally or not, drunk a glass of clear paint. 
Endoscopy_UCTN_Code_TTT_1AO_2AL

Competing interests: None

\section{J. Knuth¹, B. Krakamp², M. M. Heiss ${ }^{1}$, D. R. Bulian ${ }^{1}$}

${ }^{1}$ University of Witten/Herdecke, CologneMerheim Medical Center, Department of Abdominal, Vascular \& Transplant Surgery, Cologne, Germany

2 University of Witten/Herdecke, CologneMerheim Medical Center, Department of Internal Medicine I, Cologne, Germany

\section{References}

1 Jones GC, Coutinho K, Anjaria D et al. Treatment of recurrent Rapunzel syndrome and trichotillomania: case report and literature review. Psychosomatics 2010; 51: 443-446

2 Marcus EL, Arnon R, Sheynkman A et al. Esophageal obstruction due to enteral feed bezoar: a case report and literature review. World J Gastrointest Endosc 2010; 2: 352 356

3 Poynter BA, Hunter JJ, Coverdale JH et al. Hard to swallow: a systematic review of deliberate foreign body ingestion. Gen Hosp Psychiatry 2011; 33: $518-524$

4 Argo A, Bongiorno D, Bonifacio A et al. A fatal case of a paint thinner ingestion: comparison between toxicological and histological findings. Am J Forensic Med Pathol 2010; 31: 186-191

5 Ikenberry SO, Jue TL, Anderson MA et al, ASGE Standards of Practice Committee. Management of ingested foreign bodies and food impactions. Gastrointest Endosc 2011; 73: $1085-1091$

\section{Bibliography}

DOI http://dx.doi.org/ 10.1055/s-0032-1306790 Endoscopy 2012; 44: E184-E185 (c) Georg Thieme Verlag KG Stuttgart · New York ISSN 0013-726X

\section{Corresponding author}

J. Knuth, MD

University of Witten/Herdecke Cologne-Merheim Medical Center Department of Abdominal, Vascular and Transplant Surgery Ostmerheimer Strasse 200 Köln 51109 Germany

Fax: +49-221-89078561 jurgen.knuth@gmx.net 